\title{
Randomized Study Comparing Two Gestational Diabetes Screening Strategies in a Reference Maternity Hospital in Southern Benin
}

Ogourinde Mathieu Ogoudjobi*, Megnisse Sena HS Lokossou, Veronique Tognifode, Moufalilou Aboubakar, Anelie Kerekou, Eric Tandjiekpon, Justin Lewis Denakpo and Rene-Xavier Perrin

Department of Health Sciences, University of Abomey-Calavi, Cotonou, Benin

*Corresponding author: Ogoudjobi OM, Department of Health Sciences, University of Abomey-Calavi, Cotonou, Benin, E-mail: mogoudjobi2014@gmail.com Received date: May 12, 2018; Accepted date: June 15, 2018; Published date: June 19, 2018

Copyright: ( 2018 Ogoudjobi OM, et al. This is an open-access article distributed under the terms of the Creative Commons Attribution License, which permits unrestricted use, distribution, and reproduction in any medium, provided the original author and source are credited.

\begin{abstract}
Objective: The objective of this work is to compare two gestational diabetes screening strategies.

Patients and methods: We conducted a comparative randomized study that screened gestational diabetes on pregnant women who are between $24^{\text {th }}$ and $28^{\text {th }}$ weeks of amenorrhea. We conducted the trials either by measuring fasting glucose values or by a glucose tolerance test performed two hours after oral loading of $75 \mathrm{~g}$ glucose (WHO test). The study involved 580 pregnant women ( 290 for each type of trial) who came for antenatal appointment at the reference maternity hospital in Porto-Novo (Benin) between February $2^{\text {nd }}, 2015$ and January $31^{\text {st }}, 2017$.
\end{abstract}

Results: We detected 26 cases (9\%) of gestational diabetes by the "fasting glucose value measurement method" as compared to the 18 cases $(6.2 \%)$ detected by the WHO test, leading to a p-value of 0.209 . The two types of test were equally relevant: Sensitivity $(59.09 \%$ vs. $40.91 \%)$, specificity $(50.75 \%$ vs. $49.25 \%)$, positive predictive value $(8.97 \%$ vs. $6.21 \%)$, and predictive value negative $(93.79 \%$ vs. $91.03 \%)$. All pregnant women tested "negative" between their $24^{\text {th }}$ and their $28^{\text {th }}$ weeks of amenorrhea, were tested again during the $32^{\text {nd }}$ week of amenorrhea, using the $\mathrm{WHO}$ test method and no new case of gestational diabetes was detected.

Conclusion: Fasting glucose value measurement method can be an alternative method for gestational diabetes screening in a population where the WHO test is not available.

Keywords: Gestational diabetes screening; Fasting glucose; WHO test

\section{Introduction}

Gestational diabetes is a glucose tolerance disorder that leads to different levels of hyperglycemia and is diagnosed for the first time during pregnancy, with blood glucose levels above normal but still below the established thresholds for the diagnosis of diabetes [1-4].

Several screening strategies are proposed in the literature. During the first pregnancy trimester, the French National College of Gynecologists Obstetricians (CNGOF) and the International Association of Diabetes and Pregnancy Study Groups (IADPSG) recommend fasting glucose value measurement for women that present risk factors of gestational diabetes $[1,2,4]$. Between $24^{\text {th }}$ and $28^{\text {th }}$ weeks of amenorrhea (WA), the screening strategy is usually based on the glucose tolerance test after oral loading of a given amount of glucose [1-5].

This last method is not always available in peripheral maternity hospitals in developing countries, including Benin.

The objective of this work is to compare two gestational diabetesscreening strategies to propose an accessible strategy to a population that has limited resources.

\section{Patients and methods}

We conducted the study in the maternity service of the reference hospital of Porto-Novo (southern Benin). We conducted the study between February $2^{\text {nd }}, 2015$ and January $31^{\text {st }}, 2016$. It was a randomized analytical study with prospective data collection. It concerned the pregnant patients seen in prenatal consultation between $24^{\text {th }}$ and $28^{\text {th }} \mathrm{WA}$ and having agreed to participate at the study. We excluded the patients that were diagnosed with diabetes or a disturbed glycemic profile before or at the beginning of their pregnancy. We formed two groups of patients. The first group referenced as "Group A" was screened using:

Fasting glucose value measurement: Those patients in "Group A" were diagnosed with gestational diabetes when the result of the test was $\geq 0.92 \mathrm{~g} / \mathrm{l}$ but less than $1.26 \mathrm{~g} / \mathrm{l}$. The second group referenced as "Group B" was screened using the WHO test consisting in a glucose tolerance test performed after oral loading of $75 \mathrm{~g}$ of glucose. Patients in this group were diagnosed with gestational diabetes when the result of the test was $\geq 1.40 \mathrm{~g} / \mathrm{l}$. Two sealed envelopes, each bearing the words "Group A" or "Group B" were put in an urn. At admission, we grouped the patients in pairs. In each pair, the first patient admitted was asked to blindly pick one of the two envelopes. This patient was labeled with the mention on this envelop so that if the $1^{\text {st }}$ patient pick "Group A", the $2^{\text {nd }}$ patient is directly classified in "Group B" and vice versa. All pregnant women of both groups (A and $\mathrm{B}$ ) who were screened negative between their $24^{\text {th }}$ and $28^{\text {th }}$ weeks of amenorrhea were tested again in their $32^{\text {nd }}$ week of amenorrhea. To compare the results, the Chi-square test was used with a threshold of significance set at $5 \%$. The relevance 
Citation: Ogoudjobi OM, Lokossou MSHS, Tognifode V, Aboubakar M, Kerekou A, et al. (2018) Randomized Study Comparing Two Gestational Diabetes Screening Strategies in a Reference Maternity Hospital in Southern Benin. Clinics Mother Child Health 15: 295. doi: $10.4172 / 2090-7214.1000295$

Page 2 of 5

of the two tests was assessed by the calculation of the sensitivity, the specificity, and the positive and negative predictive values. Oral consent was obtained for each pregnant woman. The confidentiality of the data and the anonymity of the patients were ensured.

\section{Ethical aspects}

The study has been carried out with the approval of administrative authorities at different levels. Pregnant participation was voluntary. A clear explanation was given to pregnant before inclusion and no pregnant was required. Confidentiality and anonymity of the data have been respected.

\section{Results}

At the end of the study, 602 pregnant patients were eligible, but 580 met our inclusion criteria, including 290 in each group.

\section{Socio-demographic profile of the patients (pregnant women)}

The average age of the patients was 28.47 -years-old \pm 5.73 years in "Group A" and 28.18-years-old \pm 5.71 years in group "B". Pregnant women aged 35-years-old and above were the least represented $(16.5 \%$ in "Group A" vs. $14.5 \%$ in "Group B", p>0.05).

\begin{tabular}{|c|c|c|c|}
\hline & Group A (290) Number (\%) & Group B (290) Number (\%) & $p$-value \\
\hline \multicolumn{4}{|l|}{ Age (in years) } \\
\hline$(15-25)$ & $78(26.9)$ & $72(24.8)$ & \multirow[t]{3}{*}{0.305} \\
\hline$(25-35)$ & $164(56.6)$ & $176(60.7)$ & \\
\hline$\geq 35$ & $48(16.5)$ & $42(14.5)$ & \\
\hline \multicolumn{4}{|l|}{ Profession } \\
\hline Tradeswomen & $110(37.9)$ & $120(41.4)$ & \multirow[t]{5}{*}{0.487} \\
\hline Housewives & $60(20.7)$ & $62(21.4)$ & \\
\hline Workers & $44(15.2)$ & $34(11.7)$ & \\
\hline Public servant & $54(18.6)$ & $42(14.5)$ & \\
\hline Student & $22(7.6)$ & $32(11.0)$ & \\
\hline \multicolumn{4}{|l|}{ Education } \\
\hline Schooled & $246(84.8)$ & $252(86.9)$ & \multirow[t]{2}{*}{0.475} \\
\hline Unschooled & $44(15.2)$ & $38(13.1)$ & \\
\hline \multicolumn{4}{|l|}{ Marital status } \\
\hline Married & $230(79.3)$ & $214(73.8)$ & \multirow[t]{3}{*}{0.113} \\
\hline Divorced & $36(12.4)$ & $38(13.1)$ & \\
\hline Single & $24(8.3)$ & $38(13.1)$ & \\
\hline
\end{tabular}

Table 1: Socio-demographic profile of the patients.

Nearly $3 / 4$ of the pregnant patients in our sample $(73.8 \%$ in Group A vs. $74.5 \%$ in Group $\mathrm{B}, \mathrm{p}>0.05)$ were from a profession that does not benefit from state health insurance (shopkeepers, homemakers, workers). The two groups were comparable in terms of their sociodemographic profile (Table 1).

\section{Clinical characteristics of the patients (pregnant women)}

Gestational diabetes risk factors such as obstetrical history of macrosomia childbirth, stillbirths and more than two spontaneous miscarriages; body mass index $\geq 25 \mathrm{~kg} / \mathrm{m}^{2}$ before pregnancy, a family history of first-degree diabetes and a personal history of hypertension were found to be almost identical between the two groups (Table 2).

\begin{tabular}{|l|l|l|l|}
\hline \multicolumn{2}{|l|}{} & Group A Number (\%) & Group B Number (\%) \\
\hline Average number of gestations & $44(15.2)$ & $54(18.6)$ & 0.733 \\
\hline Primigravida (1) & $142(48.9)$ & $146(50.4)$ & \\
\hline Gravida 2 or 3 (2-3) & & \\
\hline
\end{tabular}


Citation: Ogoudjobi OM, Lokossou MSHS, Tognifode V, Aboubakar M, Kerekou A, et al. (2018) Randomized Study Comparing Two Gestational Diabetes Screening Strategies in a Reference Maternity Hospital in Southern Benin. Clinics Mother Child Health 15: 295. doi: $10.4172 / 2090-7214.1000295$

Page 3 of 5

\begin{tabular}{|c|c|c|c|}
\hline Multigravida ( $\geq 4$ ) & $104(35.9)$ & $90(31.0)$ & \\
\hline \multicolumn{4}{|l|}{ Average parity } \\
\hline Nulliparous (0)/Primiparous (1) & $128(44.1)$ & $126(43.4)$ & \multirow[t]{3}{*}{0.647} \\
\hline Parity 2 to $3(2-3)$ & $120(41.4)$ & $118(40.7)$ & \\
\hline Multiparous $(\geq 4)$ & $42(14.5)$ & $46(15.9)$ & \\
\hline \multicolumn{4}{|l|}{ Other obstetrical antecedents } \\
\hline Record of stillbirth & $48(16.6)$ & $38(13.1)$ & 0.243 \\
\hline Record of more than $2 \mathrm{SM}^{*}$ & $78(26.9)$ & $72(24.8)$ & 0.569 \\
\hline Record of macrosomia & $8(2.8)$ & $12(4.1)$ & 0.363 \\
\hline \multicolumn{4}{|l|}{ Medical antecedents } \\
\hline Individual high blood pressure & $8(2.8)$ & $10(3.4)$ & 0.632 \\
\hline Overweight $\left(\mathrm{BMI}^{* *} \geq 25 \mathrm{~kg} / \mathrm{m}^{2}\right)$ & $106(36.6)$ & $104(35.9)$ & 0.863 \\
\hline $1^{\text {st }}$ degree diabetes in the family & $32(11.0)$ & $42(14.5)$ & 0.213 \\
\hline Family high blood pressure & $24(8.3)$ & $32(11.0)$ & 0.261 \\
\hline
\end{tabular}

Table 2: Distribution of patients according to their antecedents.

\section{Strategies for gestational diabetes screening}

26 patients (9\% of Group A) were tested positive with gestational diabetes in Group A and 18 patients (6.2\% of Group B) were tested positive in group $B(\mathrm{p}=0.209)$ (Table 3$)$. The 536 pregnant patients for whom the result turned to be negative within their $24^{\text {th }}$ and their $28^{\text {th }}$ week of amenorrhea using both testing methods went through a second screening test in their $32^{\text {nd }}$ week of amenorrhea using the WHO test method. We discovered no new case of gestational diabetes. In total, both methods detected 44 cases of gestational diabetes, an overall prevalence of $7.6 \%(44 / 580)$.

In terms of relevance, the fasting glucose value measurement and the WHO test enabled the detection of gestational diabetes with comparable results: sensitivity (59.09\% vs. $40.91 \%)$, specificity $(50.75 \%$ vs. $49.25 \%)$, positive predictive value (8.97\% vs. $6.21 \%)$, and negative predictive value (93.79\% vs. $91.03 \%)$.

\begin{tabular}{|c|c|c|c|c|c|}
\hline & \multicolumn{2}{|c|}{$\begin{array}{l}\text { Fasting blood glucose test } n \\
(\%)\end{array}$} & \multicolumn{2}{|c|}{ Test OMS n (\%) } & \multirow[t]{2}{*}{$\mathbf{p}$} \\
\hline & Positive & Negative & Positive & Negative & \\
\hline $24-28 S A$ & $26(9.0)$ & $264(91.0)$ & $18(6.2)$ & $272(93.8)$ & 0.209 \\
\hline $32 \mathrm{SA}$ & 0 & -- & 0 & $536(100)$ & \\
\hline Total & 290 & & 290 & & \\
\hline
\end{tabular}

Table 3: Distribution of pregnant patients as per the screening method used.

\section{Discussion}

The pregnant patients in our study were in poor socio-economic conditions, which limit access of those women to health care services. It is in light of their poor socio-economic condition that we proposed fasting blood glucose as a screening test in this study. Once considered a rare disease in Africa, gestational diabetes is becoming more and more frequent, probably because of the diet that tends to align with that in developed western countries. The prevalence of gestational diabetes in our series was $7.6 \%$. The difference of the prevalence rates depending on the screening method used was not significant $(9 \% \mathrm{vs}$. $6.2 \%, \mathrm{p}>0.05)$. In Africa, the few studies carried out have reported a prevalence ranging from $5 \%$ to $17 \%$ [6-8]. In France, the prevalence of gestational diabetes ranges from $2 \%$ to $6 \%[1,9]$.

\section{Strategies of gestational diabetes screening}

In the literature, fasting glucose value measurement is the only method that can detect as many cases of gestational diabetes as possible. The "HAPO" international study, which included nearly 24,000 women, made the following findings. Out of the patients diagnosed according to the criteria of the International Association of Diabetes and Pregnancy Study Groups (IADPSG), 55\% had an abnormal level of fasting glucose, $55 \%$ had an abnormal level of blood glucose at $1 \mathrm{~h}$ and $38 \%$ had an abnormal level of blood glucose at $2 \mathrm{~h}$ [7]. In our study, we used the fasting glucose method to screen $100 \%$ of gestational diabetes cases in Group A. In fact, out of the 290 pregnant patients who were subject to fasting blood glucose test, we detected 26 cases of gestational diabetes in-between the $24^{\text {th }}$ and the $28^{\text {th }}$ week of amenorrhea. We tested the remaining patients in their $32^{\text {nd }}$ week of amenorrhea, using the WHO method. We detected no new case. 
Citation: Ogoudjobi OM, Lokossou MSHS, Tognifode V, Aboubakar M, Kerekou A, et al. (2018) Randomized Study Comparing Two Gestational Diabetes Screening Strategies in a Reference Maternity Hospital in Southern Benin. Clinics Mother Child Health 15: 295. doi: $10.4172 / 2090-7214.1000295$

Page 4 of 5

In the literature, several gestational diabetes-screening strategies are proposed, but there are always reflections on the strategy to adopt for good accessibility and good adherence of the patients.

In the first trimester, in the presence of risk factors, practitioners recommend to use fasting blood glucose screening method.

Between the $24^{\text {th }}$ and the $28^{\text {th }}$ week of amenorrhea, there are two diagnostic methods; the most recommended is currently the WHO test [1-5].

In 2010, the International Association of Diabetes Pregnancy Study Group (IADPSG) proposed an international consensus, on the ground of the data and results provided by the HAPO study [4,10-12]. The IADPSG advocated for an early screening, i.e. performed during the first trimester of pregnancy, and performed to detect pre-gestational diabetes that a fasting blood glucose test, $\mathrm{HbA1c}$ or a random blood glucose level check would have missed. Between the $24^{\text {th }}$ and the $28^{\text {th }}$ week of amenorrhea, the IADPSG recommends the fasting blood glucose test (threshold $0.92 \mathrm{~g} / \mathrm{l}$ ) and/or a blood glucose test at $1 \mathrm{~h}$ after an oral load of $75 \mathrm{~g}$ of glucose (threshold $1.80 \mathrm{~g} / \mathrm{l}$ ) and/or a blood glucose test at $2 \mathrm{~h}$ (threshold $1.53 \mathrm{~g} / \mathrm{l}$ ).

For simplicity and compliance reasons a number of African countries such as Cameroon have opted for a 2-step strategy based on the recommendations of the IADPSG [13]:

The first step consists in a fasting glucose test performed between the $24^{\text {th }}$ and the $28^{\text {th }}$ week of amenorrhea:

- If blood glucose $<0.80 \mathrm{~g} / \mathrm{l}(4.4 \mathrm{mmol} / \mathrm{l}$, it is unlikely that the patient has developed gestational diabetes; no specific action is to be taken.

- If fasting blood glucose is between $0.80 \mathrm{~g} / \mathrm{L}(4.4 \mathrm{mmol} / \mathrm{L})$ and 0.92 $\mathrm{g} / \mathrm{L}(5.1 \mathrm{mmol} / \mathrm{L})$, it is not possible to come up with a final diagnosis at this stage. A hyperglycemia is induced by oral load of glucose or a second blood glucose test is performed to conclude.

- If the fasting blood glucose $>0.92 \mathrm{~g} / \mathrm{L}(5.1 \mathrm{mmol} / \mathrm{L})$, the diagnosis of gestational diabetes can be made.

The $2^{\text {nd }}$ step is indicated if the fasting blood glucose test is between $0.80 \mathrm{~g} / \mathrm{L}(4.4 \mathrm{mmol} / \mathrm{L})$ and $0.92 \mathrm{~g} / \mathrm{L}(5.1 \mathrm{mmol} / \mathrm{L})$. This consists in a glucose tolerance test performed after oral loading of $75 \mathrm{~g}$ of glucose over $2 \mathrm{~h}$ (according to the WHO).

Out of all international recommendations, the International Association of Diabetes Pregnancy Study Group (IADPSG) and the WHO tests are the benchmark strategies for screening gestational diabetes. Many studies have shown the superiority of IADPSG screening method over the WHO test. This was the case of the Jenum study, which found $30.5 \%$ of gestational diabetes with the IADPSG test versus $13 \%$ with the WHO test [14]. Even though the IADPSG test is successful, the fact remains that its affordability remains limited in developing countries. To address this situation, some teams have adopted the fasting blood glucose test as a gestational diabetes screening strategy. This was our choice in this study. The reduced number of cases detected in each group, 26 cases in the fasting glucose group and 18 cases in the WHO group, do not allow us to conclude that one method is better than the other.

Fasting blood glucose testing has the advantage of being fairly simple and accessible to all health facilities as well as to populations in a country with limited resources.

\section{Prognosis}

Many studies have shown that patients with gestational diabetes are at high risk of developing pre-eclampsia and urinary tract infection $[1,6,15-17]$, as the infection is often related to hyperglycemia. Maternal complications noted in our study were in most of the cases urinary tract infection and pre-eclampsia, but without influence by diagnostic criteria.

Moreover, gestational diabetes is often correlated with perinatal complications such as macrosomia, immediate neonatal distress, early neonatal hypoglycemia, and neonatal death. The latter was related to uncorrected neonatal hypoglycemia due to the "third delay" [1,18-21]. In our series, we also found these complications and without influence by the diagnostic criteria.

\section{Conclusion}

The results obtained for gestational diabetes screening were comparable for the two groups of pregnant patients. The fasting blood glucose level of the IADPSG can be an alternative for gestational diabetes screening in a population where the WHO test is not accessible.

\section{Conflict of Interest}

None.

\section{References}

1. Collège National des Gynécologues et Obstétriciens Français (CNGOF), Société Francophone du Diabète (SFD) (2010): Recommandations pour la pratique Clinique: Le diabète gestationnel. J Gynecol Obstet Biol Reprod 39: S1-S342.

2. OMS (2016) Rapport mondial sur le diabète. Organisation Mondiale de la Santé 1-88.

3. Vanderijst JF, Debiève F, Doucet F, Emonts P, Haumont S, et al. (2012) Stratégie de dépistage et critères diagnostiques du diabète gestationnel. Propositions du Groupement des Gynécologues Obstétriciens de Langue Française de Belgique (GGOLFB). Louvain Med 131: 193-198.

4. Pirson N, Maiter D, Alexopoulou O (2016) Prise en charge du diébète gestationnel en 2016: Une revue de la littérature. Louvain Med 135: 661-668.

5. Sacks DA, Hadden DR, Maresh M, Deerochanawong C, Dyer AR, et al. (2012) Frequency of gestational diabetes mellitus at collaborating centers based on IADPSG Consensus panel-recommended criteria. Diabetes Care. Mars 35: 526-528.

6. Touzet S, Rocher S, Dureau-Drevard E (2002) Etude dobservation des pratiques de dépistage du diabète gestationnel à partir d'une cohorte de 701 femmes. J Gynecol Obstet Biol Reprod 31: 248-255.

7. Damoune I, El Ouahabi H, Ajdi F (2014) P51 Facteurs de risque du diabète gestationnel à propos de 100 cas. Diabetes Metab 40: A42

8. Motala A, Ramaiya K (2010) Diabète: La pandémie silencieuse et son impact en Afrique subsaharienne. African Changing Diabetes Leadership, Johannesbourg. Novo Nordisk. Diabetes Laedership Forum Africa 1-48.

9. Bensalem S, Lakehal A, Roula D (2014) Le diabète gestationnel dans la commune de Constantine, Algérie: Etude prospective. Médecine des Maladies Métaboliques. 8: 216-220.

10. Metzger BE, Gabbe SG, Persson B (2010) International association of diabetes and pregnancy study groups recommendations on the diagnosis and classification of hyperglycemia in pregnancy. Diabetes Care 33: 676-682.

11. Regnault N, Salanave B, Castetbon K, Cosson E, Vambergue A, et al. (2016) Diabète gestationnel en France en 2012: Dépistage, prévalence et 
Citation: Ogoudjobi OM, Lokossou MSHS, Tognifode V, Aboubakar M, Kerekou A, et al. (2018) Randomized Study Comparing Two Gestational Diabetes Screening Strategies in a Reference Maternity Hospital in Southern Benin. Clinics Mother Child Health 15: 295. doi: $10.4172 / 2090-7214.1000295$

Page 5 of 5

modalités de prise en charge pendant la grossesse. Bull Epidémiol Hebd 164-173.

12. Vanderijst JF, Debiève F, Doucet F, Emonts, Patrick, et al. (2012) Stratégie de dépistage et critères diagnostiques du diabète gestationnel. Louvain Med 131: 193-198.

13. Sobngwi E, Sobngwi J, Limen S, Nguewa JL, Mbanya JC (2010) Document de synthèse sur le diabète gestationnel au Cameroun. In: International Association of Diabetes and Pregnancy Study Groups. Recommendations on the diagnosis and classification of hyperglycemia in pregnancy. Diabetes Care 33: 676-682.

14. Jenum AK, Morkid K, Sletner L, Vange S, Torper JL, et al. (2012) Impact of ethnicity on gestational diabetes identied with the WHO and the modified Internationnal Association of Diabetes and Pregnancy study groups criteria: a population based cohort study. Eur J Endocrinal 166: 317-324.

15. Beucher G, Lesegno VB, Dreyfus M (2010) Maternal outcome of gestational diabetes mellitus. Diabetes Metab 36: 522-537.

16. HAPO Study Cooperative Research Group, Metzger BE, Lowe LP, Dyer AR, Trimble ER (2008) Hyperglycemia and adverse pregnancy outcomes. N Engl J Med 358: 1991-2002.
17. Yogev, Chen, Hod, Coustan, Oats (2010) HAPO Study Cooperative Research Group. Hyperglycemia and Pregnancy Outcome: preeclampsia. Am J Obstet Gynecol 202: 255e1-7.

18. Evers IM, de Valk HW, Mol BW, ter Braak EW, Visser GH (2002) Macrosomia despite good glycaemic control in type I diabetic Pregnancy; results of a nationwide study in the Netherlands. Diabetologia 45: 1484-1489.

19. Ter Braak EW, Evers IM, Erkelens DW, Visser GHA (2002) Maternal hypoglycemia during pregnancy in type I diabetes: maternal and fetal consequences. Diabetes Metab Res Rev 18: 96-105.

20. Metzger BE, Persson B, Lowe LP, Dyer AR, Cruickshank JK, et al. (2010) Hyperglycemia and adverse pregnancy outcome study: neonatal glycaemia. Pediatrics 126: e1545-e1552.

21. Hedderson MM, Weiss NS, Sacks DA, Pettitt DJ, Selby JV, et al. (2006) Pregnancy weight gain and risk of neonatal complications: macrosomia, hypoglycemia and hyperbilirubinemia. Obstet Gynecol 108: 1153-1161. 